\title{
Environmental and Food Allergens Reactivity and its Association with Total IgE, Age and Gender in Karachi, Pakistan
}

\author{
Noreen Abbas, Ahmed Raheem, Farooq Ghani ${ }^{*}$
}

*Department of Pathology and Laboratory Medicine, Aga Khan University, Karachi, Pakistan

*Corresponding author: Ghani F, Department of Pathology and Laboratory Medicine, Aga Khan University, Karachi, Pakistan, Tel: 922134930051 ; Fax: 92213493 4294; E-mail: farooq.ghani@aku.edu

Received date: May 20, 2015; Accepted date: June 19, 2015; Published date: June 26, 2015

Copyright: ( 2015 Abbas N, et al. This is an open-access article distributed under the terms of the Creative Commons Attribution License, which permits unrestricted use, distribution, and reproduction in any medium, provided the original author and source are credited.

\begin{abstract}
Aim: The aim of this study is to assess the frequency of food and environmental allergens reactivity and its association in with age, gender and total IgE levels

Material and methods: The study population consisted of 88 individuals including children and adults (male: 47 and female: 41). The study was conducted in the clinical laboratory, Department of Pathology and Laboratory Medicine, Aga Khan University Hospital from May 2009 till May 2010. Sera of patients positive for total IgE were tested for allergen specific IgE levels by Immulite 2000, 3gAllergyTM. We divided allergens into two panels, namely food and environmental.

Results: There were a total of 27 allergens tested on 88 individuals who had elevated levels of total IgE. Median age was 18 yrs. (IQR 8-36). We have analyzed the data on two cutoffs of allergen specific IgE reactivity i.e. moderate $(0.7-3.49 \mathrm{kU} / \mathrm{L})$ and high $(3.5-17.49 \mathrm{kU} / \mathrm{L})$. In the environmental allergens group the moderate rates of reactivity were to dog epithelium $(46.6 \%)$, mites $(33 \%)$ and cockroach. $(17 \%)$. From food panel moderate reactivity were to egg white $(23.9 \%)$, milk $(22.7 \%)$ and soybean $(13.6 \%)$. High reactivity rates were seen to mites $(6.8 \%)$, cockroach $(4.5 \%)$, cat dander epithelium $(3.4 \%)$, D.farinae $(3.4 \%)$, molds $(3.4 \%)$ and weeds $(3.4 \%)$. Commonest food allergens with high reactivity were egg white $(2.3 \%)$, peanuts $(2.3 \%)$ and shrimps $(2.3 \%)$. Very high reactivity of environmental allergens $(>52.50 \mathrm{kU} / \mathrm{L})$ were mites $(2.3 \%)$, cat dander epithelium $(1.1 \%)$ whereas in food panel it was shrimps $(1.1 \%)$ and peanuts $(1.1 \%)$. Positive significant association of food allergens reactivity is seen with gender $(p=0.01)$, age $(p \leq 0.001)$ and total $\operatorname{lgE}(p=0.05)$. On the other hand positive significant association of environmental allergens reactivity is seen with age $(p=0.02)$ and total $\lg E(p \leq 0.001)$.
\end{abstract}

Conclusion: Mites, cat dander, dog epithelium and cockroach were the most frequent environmental allergens and egg white, peanuts and shrimps were the most prevalent food allergens. There was a positive correlation between age, gender, total IgE levels and IgE specific allergens. Our study demonstrates high rates of reactivity to major environmental and food allergens in patients with high total IgE.

Keywords: Total IgE; Allergen specific IgE; Reactivity; Food Allergens; Environmental allergens

\section{Introduction}

Many allergens present in the environment can trigger allergic response in atopics. Generally, atopics are sensitive to more than one allergen [1] Environmental factors and lifestyles are major determinants of the increase in prevalence and severity of these allergic diseases [2]. There is accumulating evidence that both genetic and environmental factors play an important role in the etiology of allergic diseases and it is likely that there is a multilevel interaction between these factors [3]. Changes of lifestyle in industrialized countries have led to a decrease of the infectious burden and are associated with the rise of allergic and autoimmune diseases, according to the chygiene hypothesis'. The hypothesis was first proposed by Strachan, who observed an inverse correlation between hay fever and the number of older siblings when following more than 17000 British children born in 1958 [4].
The role of dietary factors in the development of asthma and atopy is still controversial. It has been postulated that the decrease in vegetable consumption and a shift from animal towards vegetable fat consumption has contributed to the increase in the asthma and allergic diseases over the last decades [4]. The common food allergens causing reaction in children and adults are milk, egg, wheat, soy, peanuts, tree nuts, fish and shell fish. While majority of children will outgrow milk, egg, wheat and soy allergy, hypersensitivity to peanuts, tree nuts, fish and shell fish is often lifelong [5]. The allergic diseases are on the rise globally, and Pakistan is no exception. There are no national registries available to document the prevalence of allergic diseases related to environmental and food factors. However, individual efforts have been done and prevalence of allergic diseases was studied in all four provinces of Pakistan. In this study they reported that during the year 2007 , out of 41,213 patients, 27,283 (66.1\%) were diagnosed with various allergic diseases by skin prick test to aeroallergens (dust, pollens, paper mulberry, thresher and raw cotton) and food allergens (beef, mutton, chicken, egg, fish and rice). They were between ages 12 years to 55 years with 35 as median age. The male female patient ratio was $2: 1$ with $60 \%$ male and $30 \%$ female [1]. With such high prevalence 
Page 2 of 6

of allergic diseases there were no testing options available in various cities of Pakistan. In another study they focused on food allergies and concluded that food allergy affects $4-6 \%$ of the children, with its prevalence apparently increasing with the increasing prevalence of extrinsic asthma and environmental allergies [6]. Misdiagnosed or untreated childhood allergies can lead to serious problems in adulthood, including asthma and prevalence of clinical asthma in Pakistan is $4.3 \%$ [7-10]. The potential to cause troublesome reactions and their increasing prevalence highlight the necessity of accurate diagnosis and treatment of food allergies. The purpose of this study was to know the frequency of environmental and food allergens causing increased prevalence of asthma, rhinitis and atopic eczema and skin allergies in our people effecting quality of life and has an economic impact in due to their high prevalence [10]. Early diagnosis of atopic diseases makes it possible to begin preventive measures, which reduces the clinical expression of allergic diseases. Therefore, understanding the frequency of allergen reactivity is important for the better clinical diagnosis, early prevention and focused patient care.

\section{Objective}

To assess frequency of food and environmental allergens in patients having high total IgE levels and its association with age and gender

\section{Materials and Methods}

\section{Study population and procedure}

A cross sectional study was conducted in the Section of Chemical Pathology, Department of Pathology and Laboratory Medicine in collaboration with the Clinical allergist, Department of Medicine, Aga Khan University, Karachi Pakistan. It was conducted over a period of six months from August 2013 to October 2013. The institutional ethical review committee has exempted the study as minimal patient involvement was there. Laboratory data was reviewed and patients with high total IgE levels and 88 were recruited for analysis of specific IgE against 27 food and environmental allergens. Aliquots were made from serum separator tubes for analysis of various food and environmental allergen by $3 \mathrm{~g}$ allergen specific IgE assay. Allergen specific IgE is a solid phase two-step, chemiluminescent immunoassay that exploits liquid phase kinetics in a bead format. The allergens are covalently bound to a soluble polymer/co-polymer matrix, which in turn is labelled with ligand.

\section{Biochemical measurements}

Serum samples having high total IgE were identified and centrifuged at $1000 \mathrm{~g}$ for 12 minutes, aliquoted, frozen and maintained at $-80^{\circ} \mathrm{C}$. All samples were run in batches for various food and environmental allergens. Allergens were measured by $3 g$ allergen specific IgE on automated chemiluminescent immunoassay by Immulite 2000. Food group included 10 allergens i.e. codfish, peanuts, lentil, milk, shrimps, soybean, rice, egg white, wheat and beef. Environmental allergens group included cat dander epithelium, dog epithelium, cockroach, $D$. pteronyssinus and $D$. farinae, p.notatum, $C$. herbarum, A. fumigatus, A. tenuis and C. lunata, eucalyptus, acacia, mesquite, E. plantain, L. quater, $R$. thistle and $R$. pigweed. These panels were assessed on five levels of specific IgE reactivity (table 1 ). To ensure quality, normal and abnormal controls were run with every batch of food and environment allergens analysis.

\begin{tabular}{|c|c|c|}
\hline Class & kU/L & $\begin{array}{c}\text { Reactivity for } \\
\text { Individual/Component } \\
\text { Allergen(s) }\end{array}$ \\
\hline \multirow{2}{*}{0} & $<0.10$ & Absent or Not Detected \\
\cline { 2 - 3 } & $0.10-0.34$ & Very Low \\
\hline I & $0.35-0.69$ & Low \\
\hline III & $0.70-3.49$ & Moderate \\
\hline IV & $3.50-17.49$ & High \\
\hline V & $17.5-52.49$ & Very High \\
\hline VI & $52.5-99.99$ & \multirow{2}{*}{} \\
\hline
\end{tabular}

Table 1: Interpretation of allergen specific IgE values according to reactivity.

\section{Statistical analysis}

Data were collected, managed, entered and analyzed by SPSS version 19. Descriptive analyses of all variable in the study were performed. Data were also analyzed for inferential statistics. In order with respect to analyze the profile of the sample according to the variables studied, frequency tables for categorical variables like (gender, age group) were created. Male:Female ratio was also computed. The descriptive statistics like (mean, standard deviation, minimum and maximum values) for continuous variable like (age, Total IgE, specific IgE allergens of food and environment) etc. was computed. The correlation between the Total IgE and specific IgE allergen (food and Environmental) was analyzed by spearmen correlation. In order to assess the relationship between IgE and age, we calculated Kendall's tau-b and the corresponding p-values to test the hypothesis that both variables are not associated. The results were compiled, merged and apply multiple response comparison analysis, using chi square test for association between reactivity, age, gender and serum IgE levels. The level of significance for all the statistical test was $5 \%$ at $95 \%$ (C.I) $\mathrm{P}<0.05$ respectively.

\section{Results}

\section{Participant characteristics}

Total 88 sera with high total IgE were included in the study, on which 27 IgE specific allergens both from environmental and food panel were analyzed. There were 47 (53\%) males and 41 (47\%) females. Mean age of our study participants was $22 \pm 17.6$ yrs. Mean Total IgE was $663 \pm 566 \mathrm{IU} / \mathrm{ml}$. Mean \pm SD of environmental and food allergens are shown in table 2 .

\section{Frequency of IgE specific food allergens}

We have analyzed frequency at 10 food allergens at various level of reactivity of specific IgE i.e. low (0.35-0.69 kU/L), moderate (0.70-3.49 $\mathrm{kU} / \mathrm{L})$, high (3.50-99.99 kU/L) and very high (>100 kU/L). Top allergens with low reactivity were beef $(13 \%)$, wheat (7\%), egg white $(6 \%)$ and rice $(5 \%)$. Allergens with moderate reactivity were egg white $(7 \%)$, beef $(6 \%)$, shrimps $(3 \%)$, rice $(3 \%)$, soybean $(3 \%)$ and wheat 
Citation: Abbas N, Raheem A, Ghani F (2015) Environmental and Food Allergens Reactivity and its Association with Total IgE, Age and Gender in Karachi, Pakistan. J Allergy Ther 6: 215. doi:10.4172/2155-6121.1000215

Page 3 of 6

(3\%). Allergens with high reactivity of specific IgE were egg white (2\%), shrimps (2\%) and peanuts (2\%) (Figures $1 \mathrm{a}, 1 \mathrm{~b}$ and $1 \mathrm{c}$ ).

\begin{tabular}{|c|c|c|c|c|}
\hline Study Variables & Minimum & Maximum & Mean & $\begin{array}{c}\text { Std. } \\
\text { Deviation }\end{array}$ \\
\hline Age & 1 & 76 & 21.91 & 17.6 \\
\hline $\operatorname{lgE}$ & 7 & 2,000 & 662.05 & 565.9 \\
\hline
\end{tabular}

Environmental Allergens

\begin{tabular}{|c|c|c|c|c|}
\hline $\begin{array}{l}\text { Cat Dander } \\
\text { Epithelium }\end{array}$ & 0.1 & 83.1 & 1.48 & 8.9 \\
\hline Dog Epithelium & 0.1 & 1.76 & 0.19 & 0.2 \\
\hline Cockroach & 0.1 & 36.7 & 1.57 & 5.1 \\
\hline D. Pteronyssinus & 0.1 & 72.7 & 3.52 & 13.5 \\
\hline D. Farinae & 0.1 & 62.9 & 4.14 & 12.8 \\
\hline P. Notatum & 0.1 & 21.4 & 0.48 & 2.3 \\
\hline C. Herbarum & 0.1 & 2.15 & 0.16 & 0.2 \\
\hline A. Fumigatus & 0.1 & 58.8 & 2.24 & 8.3 \\
\hline A. Tenuis & 0.1 & 14.7 & 0.46 & 1.9 \\
\hline C. Lunata & 0.1 & 20 & 0.59 & 2.6 \\
\hline Eucalyptus & 0.1 & 36.5 & 0.61 & 3.9 \\
\hline Acacia & 0.1 & 53.4 & 0.91 & 5.8 \\
\hline Mesquite & 0.1 & 92.1 & 1.35 & 9.8 \\
\hline E Plantain & 0.1 & 62.8 & 0.9 & 6.7 \\
\hline L Quater & 0.1 & 12.7 & 0.43 & 1.8 \\
\hline R Thistle & 0.1 & 17.1 & 0.62 & 2.5 \\
\hline R Pigweed & 0.1 & 13.2 & 0.29 & 1.4 \\
\hline
\end{tabular}

Food Allergens

\begin{tabular}{|c|c|c|c|c|}
\hline Egg White & 0.1 & 9.55 & 0.35 & 1.1 \\
\hline Milk & 0.1 & 0.9 & 0.13 & 0.12 \\
\hline Codfish & 0.1 & 2.3 & 0.15 & 0.3 \\
\hline Wheat & 0.1 & 50 & 0.8 & 5.34 \\
\hline Rice & 0.1 & 46.3 & 0.75 & 4.9 \\
\hline Peanuts & 0.1 & 53.3 & 0.85 & 5.7 \\
\hline Soybean & 0.1 & 28.4 & 0.49 & 3 \\
\hline Shrimps & 0.1 & 90.5 & 1.45 & 9.7 \\
\hline Beef & 0.1 & 1.4 & 0.24 & 0.2 \\
\hline Lentil & 0.1 & 7.9 & 0.22 & 0.8 \\
\hline
\end{tabular}

Table 2: Descriptive and biochemical variables $(\mathrm{n}=88)$.

Abbreviations used: D. pteronyssinus: Dermatophagoides Pteronyssinus; D. farina: Dermatophagoides Farinae; P. notatum: Penicillium Notatum; C. herbarum: Cladosporium herbarum; $A$. fumigatus: Aspergillus Fumigatus; A. tenuis: Alternaria Tenuis; $C$. lunata: Cochliobolus Lunata; E. plantain: English Plantain; L. quarter: Latin Quarter; R Thistle: Russian Thistle; R Pigweed: Redroot Pigweed.
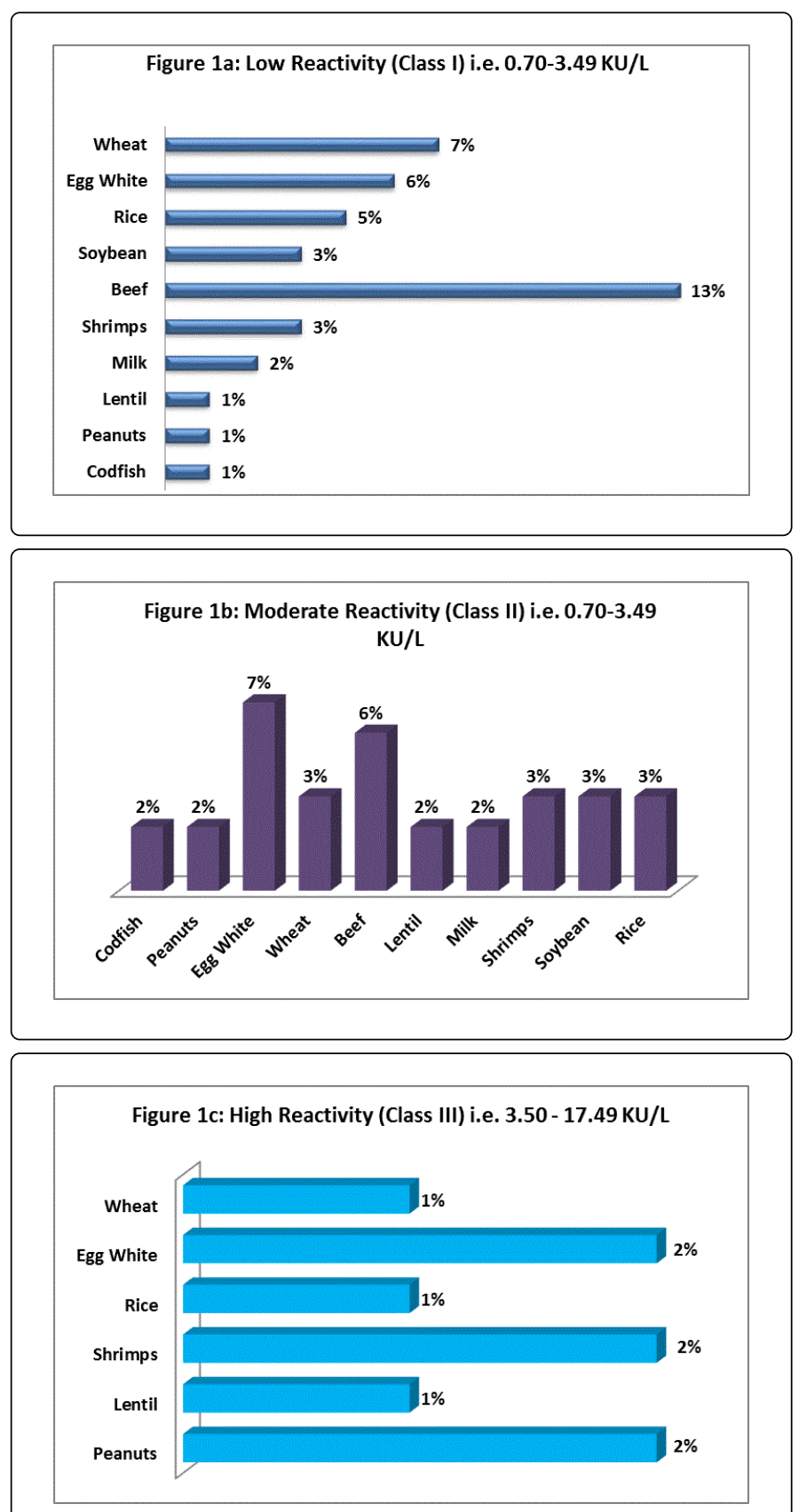

Figure 1a-c: Frequency of IgE-specific food allergens at various reactivities.

Top allergens with low reactivity were beef (13\%), wheat (7\%), egg white $(6 \%)$ and rice $(5 \%)$. Allergens with moderate reactivity were egg white $(7 \%)$, beef $(6 \%)$, shrimps $(3 \%)$, rice $(3 \%)$, soybean $(3 \%)$ and wheat $(3 \%)$. Allergens with high reactivity of specific IgE were egg white (2\%), shrimps (2\%) and peanuts (2\%) (Figures $1 \mathrm{a}, 1 \mathrm{~b}$ and $1 \mathrm{c}$ ). 
Citation: Abbas N, Raheem A, Ghani F (2015) Environmental and Food Allergens Reactivity and its Association with Total IgE, Age and Gender in Karachi, Pakistan. J Allergy Ther 6: 215. doi:10.4172/2155-6121.1000215

Page 4 of 6

\section{Frequency of IgE specific environmental allergens}

From environmental panel 17 allergens were tested and categorized of various levels of reactivity of specific IgE same as done in food allergens panel. Top allergens with low reactivity were dog epithelium (8\%), Mites (7\%) and R. thistle (7\%). Allergens with moderate reactivity were cockroach (17\%), mites (17\% and $13 \%)$ and $P$. notatum (6\%). Allergens with high reactivity of specific IgE were cat dander, mites, cockroach and $A$. fumigatus (Figures $2 \mathrm{a}, 2 \mathrm{~b}$ and $2 \mathrm{c}$ ).

Top allergens with low reactivity were dog epithelium (8\%), Mites (7\%) and R. thistle (7\%). Allergens with moderate reactivity were cockroach (17\%), mites (17\% and $13 \%)$ and $P$. notatum (6\%). Allergens with high reactivity of specific IgE were cat dander, mites, cockroach and $A$. fumigatus (Figures $2 \mathrm{a}, 2 \mathrm{~b}$ and $2 \mathrm{c}$ ).

Association of IgE specific food and environmental allergens with total IgE, age and gender:

Statistically significant positive association of food allergens reactivity is seen with gender $(\mathrm{p}=0.01)$, age $(\mathrm{p} \leq 0.001)$ and total $\operatorname{IgE}$ $(\mathrm{p}=0.05)$. On the other hand positive significant association of environmental allergens reactivity is seen with age $(\mathrm{p}=0.02)$ and total $\operatorname{IgE}(\mathrm{p} \leq 0.001)$ (Tables 3 and 4$)$.

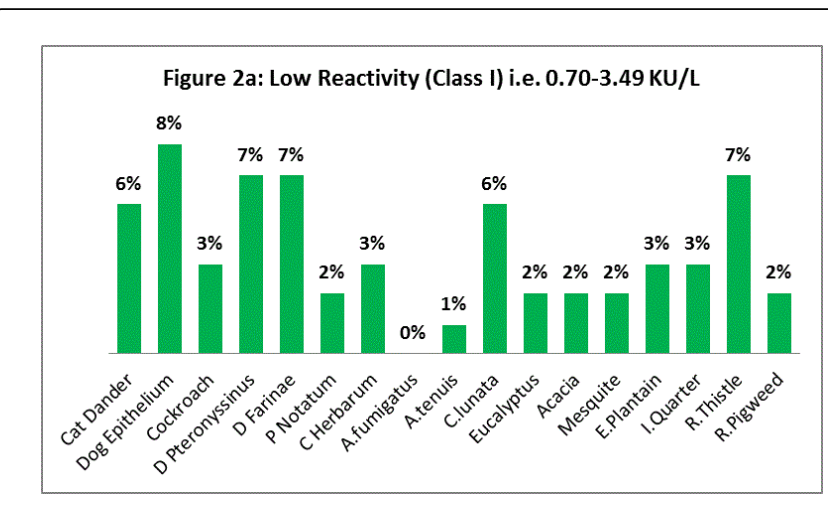

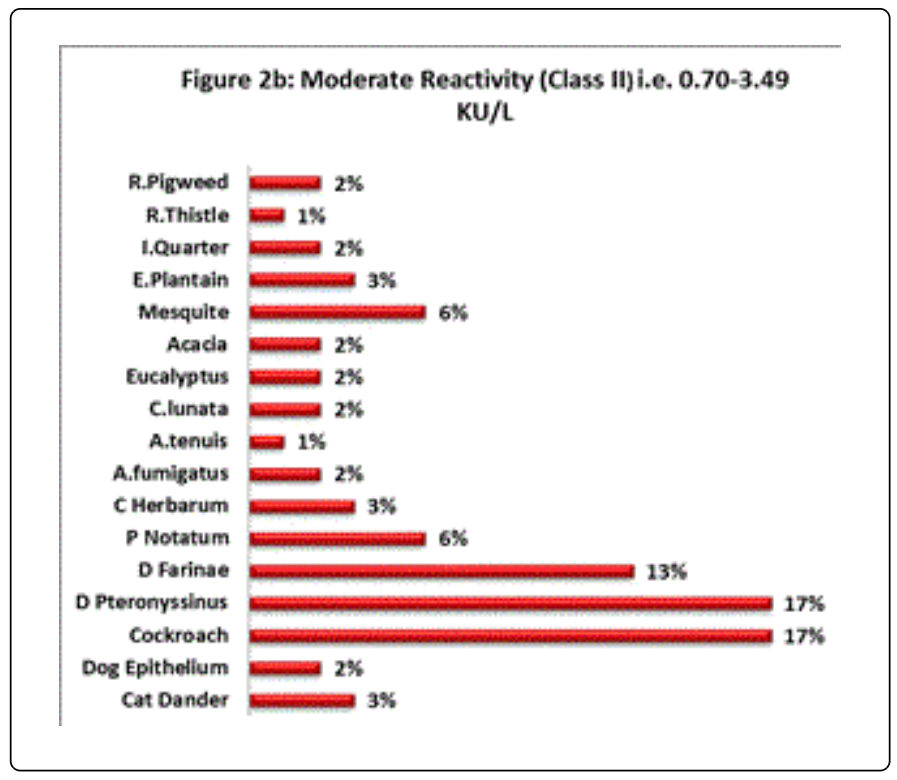

Figure 2c: High Reactivity (Class III) i.e. 3.50 - 17.49 KU/L

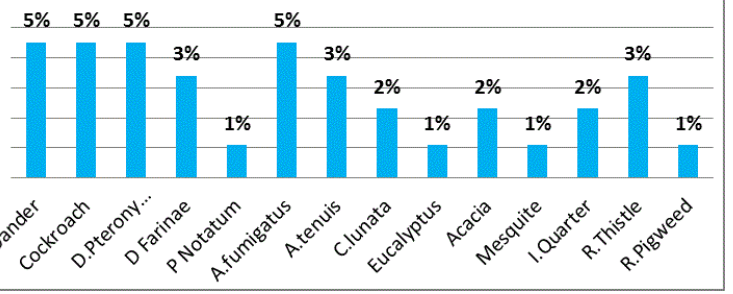

Figure 2a-c: Frequency of IgE-specific environmental allergens at various reactivities.

\begin{tabular}{|c|c|c|c|c|c|c|c|}
\hline Reactivity & $<0.10=$ Absent & $0.10-0.34=$ Very low & $0.35-0.69=$ Low & $\begin{array}{l}0.70-3.49=\text { Moderat } \\
\text { e }\end{array}$ & $3.50-17.49=\mathrm{High}$ & $\begin{array}{l}>17.50=\text { Very } \\
\text { high }\end{array}$ & $p$-value \\
\hline \multicolumn{7}{|l|}{ Gender } & \multirow{3}{*}{$0.01^{*}$} \\
\hline Male & $47(53.4 \%)$ & $29(33 \%)$ & $19(21.6 \%)$ & $24(27.3 \%)$ & $26(29.5 \%)$ & $2(2.3 \%)$ & \\
\hline Female & $40(45.5 \%)$ & $28(31.8 \%)$ & $12(13.6 \%)$ & $12(13.6 \%)$ & $33(37.5 \%)$ & - & \\
\hline \multicolumn{7}{|l|}{ Age } & \multirow{3}{*}{$0.000^{* *}$} \\
\hline$<36$ yrs. & $46(52.3 \%)$ & $34(38.6 \%)$ & $19(21.6 \%)$ & $31(35.2 \%)$ & $17(19.3 \%)$ & $1(1.1 \%)$ & \\
\hline$>36 \mathrm{yrs}$. & $41(46.6 \%)$ & $23(26.1 \%)$ & $12(13.6 \%)$ & $5(5.7 \%)$ & $42(47.7 \%)$ & $1(1.1 \%)$ & \\
\hline \multicolumn{7}{|l|}{ Total $\lg \mathrm{E}$} & \multirow{3}{*}{0.05} \\
\hline$<450$ & $43(48.9 \%)$ & $27(30.7 \%)$ & $11(12.5 \%)$ & $13(14.8 \%)$ & $27(30.7 \%)$ & $2(2.3 \%)$ & \\
\hline$>450$ & $44(50 \%)$ & $30(34.1 \%)$ & $30(34.1 \%)$ & $23(26.1 \%)$ & $32(36.4 \%)$ & - & \\
\hline \multicolumn{7}{|l|}{${ }^{*} p$ value $<0.05$} & $\mathrm{p}$-value \\
\hline
\end{tabular}

Table 3: Specific IgE reactivity of food allergens and its correlation with age, gender and total IgE. 
According to spearman statistically significant positive association of food allergens reactivity is seen with gender $(\mathrm{p}=0.01)$, age $(\mathrm{p} \leq$ $0.001)$ and total $\operatorname{IgE}(\mathrm{p}=0.05)$.

\begin{tabular}{|c|c|c|c|c|c|c|c|}
\hline Reactivity & $<0.10=$ Absent & $\begin{array}{c}0.10-0.34=\text { Very } \\
\text { low }\end{array}$ & $0.35-0.69=$ Low & $\begin{array}{c}0.70-3.49=\text { Modera } \\
\text { te }\end{array}$ & $3.50-17.49=\mathrm{High}$ & $\begin{array}{c}>17.50=\text { Very } \\
\text { high }\end{array}$ & $p$-value \\
\hline \multicolumn{7}{|l|}{ Gender } & \multirow[t]{3}{*}{0.25} \\
\hline Male & $47(53.4 \%)$ & $30(34.1 \%)$ & $12(13.6 \%)$ & $17(19.3 \%)$ & $10(11.4 \%)$ & $6(6.8 \%)$ & \\
\hline Female & $40(45.5 \%)$ & $29(33 \%)$ & $18(20.5 \%)$ & $22(25 \%)$ & $10(11.4 \%)$ & $6(6.8 \%)$ & \\
\hline \multicolumn{7}{|l|}{ Age } & \multirow[t]{3}{*}{$0.02^{*}$} \\
\hline$<36 \mathrm{yrs}$ & $44(50 \%)$ & $27(31 \%)$ & $10(11.4 \%)$ & $14(16 \%)$ & $8(9 \%)$ & $4(5 \%)$ & \\
\hline$>36 \mathrm{yrs}$ & $43(49 \%)$ & $32(36 \%)$ & $20(23 \%)$ & $25(28 \%)$ & $12(14 \%)$ & $8(9 \%)$ & \\
\hline \multicolumn{7}{|l|}{ Total IgE } & \multirow{2}{*}{$0.000^{* *}$} \\
\hline$<450$ & $44(50 \%)$ & $24(27 \%)$ & $12(14 \%)$ & $12(14 \%)$ & $4(5 \%)$ & $5(6 \%)$ & \\
\hline$>450$ & $43(49 \%)$ & $35(40 \%)$ & $18(21 \%)$ & $27(31 \%)$ & $16(18 \%)$ & $7(8 \%)$ & \\
\hline \multicolumn{7}{|l|}{${ }^{*} \mathrm{p}$ value $<0.05$} & \\
\hline
\end{tabular}

Table 4: Specific IgE reactivity of environmental allergens and its correlation with gender, age and total IgE.

According to spearman positive significant association of environmental allergens reactivity is seen with age $(\mathrm{p}=0.02)$ and total $\operatorname{IgE}(\mathrm{p} \leq 0.001)$.

\section{Discussion}

In this study we evaluated frequency of allergic reactivity to environmental and food allergens. The overall rate of reactivity in moderate group is $44.3 \%$, in high group is $22.7 \%$ and in very high group is $13.6 \%$. As reported, reactivity of allergens specific IgE plays a crucial role in the development of atopic disorders.

This is the first study from Karachi, Pakistan which has assessed the frequency of environmental and food allergens in our population and its association with age, total IgE and gender. We have found frequency of allergens at various cut offs of reactivity. In environmental group, the high reactivity allergens were cat dander epithelium, dog epithelium, cockroach, $D$. pteronyssinus (mite) and $D$. farinae (mite) in our people. High reactivity of mites is due to the fact that high temperature and high relative humidity of Karachi optimize the growth conditions for house dust mites (HDMs). These Allergens reactivity were then found to be significantly associated with age $(\mathrm{p}=0.02)$ and total IgE levels $(\mathrm{p} \leq 0.001)$. In food group, the high reactivity allergens were egg white, shrimps, beef and peanuts. These allergens were significantly associated with age $(p \leq 0.001)$, gender $(\mathrm{p}=0.01)$ and total IgE levels $(\mathrm{p}=0.05)$.

Our data are consistent with findings in other studies on different population groups. Based on the food challenge studies from Australia, Japan, Indonesia, Malaysia and the Philippines, hypersensitivity to milk and egg are the commonest food allergens. Soy, wheat and peanut hypersensitivity are next commonest, but rice allergy is rare. There is a relatively good correlation between very high levels of IgE anti-food antibodies, (reflected by skin weal size or IgE serum antibody levels for milk, egg and peanut and probably for other nuts, fish and shellfish).
However, the measurement of IgE antibodies to wheat, rice and soy are not predictive of clinical hypersensitivity [8].

Huang et al. found high prevalence of, environmental allergens i.e. house dust mites (Der p, Der f,) in his study [11]. In addition to house dust mites, a small proportion of atopic children are also sensitive to other inhaled allergens, such as cockroaches, animal dander, and fungus. Reactivity to cockroaches is considered to be a strong risk factor for asthma in children of lower socioeconomic class or children living in the inner-city. The prevalence of food allergies was estimated at $1.0 \%$ to $11.4 \%$ and represented only a small proportion of all allergies among our atopic children. However, three food allergies, including shrimp, crab, and egg white, were common in children with atopic dermatitis. Furthermore, compared to older children, younger children (2-6 years) also had higher rates of reactivity to milk, egg white, peanuts, wheat, and soybeans $[11,12]$.

There are some limitations associated with our study. As with all retrospective analyses, there may be a sample selection bias. We have attempted to minimize this weakness by applying strict laboratory inclusion criteria. Only patients with high total $\operatorname{IgE}$ levels were included in the analysis. However, a prospective assessment will be a better tool for evaluating the impact of food and environmental allergens reactivity in our population with clinical relevance.

\section{Conclusion}

Reactivity of house dust mites, cat dander and cockroaches were found to be high in environmental allergens and egg white, beef, peanut and shrimps are significant in food allergens amongst patients with increased circulating total IgE levels. Serum-specific IgE reflects an individual's susceptibility to allergen reactivity, while assays for specific IgE antibodies to suspect allergens are of greater clinical use for etiological diagnoses. 
Citation: Abbas N, Raheem A, Ghani F (2015) Environmental and Food Allergens Reactivity and its Association with Total IgE, Age and Gender in Karachi, Pakistan. J Allergy Ther 6: 215. doi:10.4172/2155-6121.1000215

Page 6 of 6

\section{References}

1. Ahmad F, Yousaf F, Asif S (2007) Prevalence of Allergic Disease and Related Allergens in Pakistan in 2007. Journal of Postgraduate Medical Institute (Peshawar-Pakistan) 25.

2. Droma Y, Kunii O, Yangzom Y, Shan M, Pingzo L, et al. (2007) Prevalence and severity of asthma and allergies in school children in Lhasa, Tibet. Clin Exp Allergy 37: 1326-1333.

3. Kanffman F, Dizier MH, Annesi MI, Bousquet J, Charpin D, et al. (1992) Epidemiological study on the genetics and environment of asthma, bronchial hyper responsive and atopy descriptive characteristics. Clin Exp Allergy 29: 17-21.

4. Okada H, Kuhn C, Feillet H, Bach JF (2010) The 'hygiene hypothesis' for autoimmune and allergic diseases: an update. Clin Exp Immunol 160: $1-9$.

5. Seaton A, Godden DJ, Brocon K (1994) Increase in asthma: a more toxic environment or a more susceptible population. Thorax 49: 171-174.

6. Wang J, Sampson HA (2007) Food anaphylaxis. Clin Exp Allergies 37: 651-660.
7. Holt PG, Macaubas C, Prescott SL, Sly PD (2000) Primary sensitization to inhalant allergens. Am J Respir Crit Care Med 162: S91-S94.

8. Nowak-Wegrzyn A (2003) Future approaches to food allergy. Pediatrics 111: 1672-1680.

9. Hill DJ, Hosking CS, Zhie CY, Leung R, Baratwidjaja K, et al. (1997) The frequency of food allergy in Australia and Asia. Environ Toxicol Pharmacol 4: 101-110.

10. Huss K, Adkinson NF, Eggleston PA, Dawson C, Van Natta ML, et al. (2001) House dust mite and cockroach exposure are strong risk factors for positive allergy skin test responses in the Childhood Asthma Management Program. J Allergy Clin Immunol 107: 48-54.

11. Singh M (2005) The burden of asthma in children: an Asian perspective. Paediatr Respir Rev 6: 14-9.

12. Huang HW, Lue KH, Wong RH, Sun HL, Sheu JN, et al. (2006) Distribution of allergens in children with different atopic disorders in central Taiwan. Acta Paediatr Taiwan 47: 127-134. 